\title{
PAMAM-CRGD mediating efficient siRNA delivery to spermatogonial stem cells
}

\author{
Tianjiao Li ${ }^{1 \dagger}$, Qiwen Chen ${ }^{2 \dagger}$, Yi Zheng ${ }^{1}$, Pengfei Zhang ${ }^{1}$, Xiaoxu Chen ${ }^{1}$, Junna Lu², Yinghua Lv², Shiguo Sun ${ }^{2^{*}}$ and \\ Wenxian Zeng ${ }^{1 *}$ (D)
}

\begin{abstract}
Background: Spermatogonial stem cells (SSCS) are the cornerstone of sperm production and thus perpetual male fertility. In clinics, transplantation of patient's own SSCs into testes is a promising technique to restore fertility when male germ cells have been depleted by gonadotoxic therapies. Auto-transplantation of genetically modified SSCs even has the potential to treat male infertility caused by genetic mutations. However, SSCs are refractory to transfection approaches. Poly(amidoamine) (PAMAM) dendrimers have the unique three-dimensional architecture, surface charge, and high density of surface groups that are suitable for ligand attachment, thereby facilitating target delivery. The goal of this study was to elucidate whether PAMAM dendrimers can efficiently deliver short interfering RNAs (siRNAs) to SSCs.

Methods and results: We introduced cyclic arginine-glycine-aspartic acid (cRGD) peptides to the fifth generation of PAMAM dendrimers (G5) to generate PAMAM-CRGD dendrimers (G5-CRGD). The characterization of G5-CRGD was detected by Fourier transform infrared spectroscope (FTIR), transmission electron microscope (TEM), and the Cell Counting Kit-8 (CCK-8) assay. Confocal microscopy and flow cytometry were used to evaluate the delivery efficiency of siRNA by G5-CRGD to SSCs. The results showed that G5-cRGD encompassing siRNA could self-assemble into spherical structures with nanoscale size and possess high transfection efficiency, excellent endosomal escape ability, and low cytotoxicity, superior to a commercial transfection reagent Lipofectamine ${ }^{\circledast} 2000$. Moreover, we demonstrated that G5-cRGD efficiently delivered siRNAs and triggered gene silencing.

Conclusions: This study thus provides a promising nanovector for siRNA delivery in SSCS, facilitating the future clinical application of SSC auto-transplantation with genetically modified cells with a hope to cure male infertility that is caused by genetic disorders.
\end{abstract}

Keywords: PAMAM-cRGD, siRNA delivery, Nanoparticle, Spermatogonial stem cells

\section{Background}

Spermatogonial stem cells (SSCs) are unique adult stem cells that transmit genetic information to subsequent generations. SSCs possess the potential of self-renewal and differentiation, thereby sustaining fertility throughout a man's life $[1,2]$. In clinics, auto-transplantation of genetically modified SSCs has the potential to treat male

\footnotetext{
* Correspondence: sunsg@nwsuaf.edu.cn; zengwenxian2015@126.com

†Tianjiao Li and Qiwen Chen contributed equally to this work.

'Key Laboratory for Animal Genetics, Breeding and Reproduction of Shaanxi Province, Key Laboratory for Animal Biotechnology, Ministry of Agriculture of China, College of Animal Science and Technology, Northwest A\&F University, Yangling, Shaanxi, China

${ }^{2}$ Shaanxi Key Laboratory of Natural Products \& Chemical Biology, College of Chemistry \& Pharmacy, Northwest A\&F University, Yangling 712100, Shaanxi, China
}

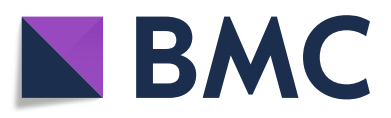

(c) The Author(s). 2019 Open Access This article is distributed under the terms of the Creative Commons Attribution 4.0 International License (http://creativecommons.org/licenses/by/4.0/), which permits unrestricted use, distribution, and reproduction in any medium, provided you give appropriate credit to the original author(s) and the source, provide a link to the Creative Commons license, and indicate if changes were made. The Creative Commons Public Domain Dedication waiver (http://creativecommons.org/publicdomain/zero/1.0/) applies to the data made available in this article, unless otherwise stated.

infertility and prevent transmission of genetic diseases to the offspring [3]. In addition, SSCs are able to generate donor-derived sperm after transplantation to a recipient's testis [4]. Thus, genetic manipulation in combination with SSC transplantation provides a robust means to produce genetically modified offspring with improved productivity and production traits in animal industry [5].

However, studies and potential applications of SSCs have been greatly hampered due to low transfection efficiency. Previous reports have shown that SSCs are refractory to calcium phosphate and lipofection-mediated transfection [6, 7]. Meanwhile, electroporation typically yields significant cell death [8-10]. In case of viral transduction, viral sequences may integrate into the recipient genome, raising safety concerns in clinics $[3,11]$. 
Therefore, there is an urgent need for development of novel strategies to deliver exogenous substances into SSCs with improved efficiency and safety.

Nanotechnology offers an attractive solution to the delivery problem. Among them, poly(amidoamine) (PAMAM) dendrimers are highly symmetric, spherical, hyper-branched, biocompatible, and nonimmunogenic $[12,13]$. Importantly, PAMAM dendrimers exhibit high density of functional groups and high buffer capacity that facilitates endosome rupture and the release into cytoplasm $[13,14]$, making them as promising vectors for drug or gene delivery [13, 15]. Ziraksaz et al. reported that PAMAM could efficiently knock down octamer-binding transcription factor 4 (Oct4) gene expression in mouse embryonic stem cells [16]. However, cytotoxicity as well as poor targeting limits its application. Fortunately, modification with cyclic arginine-glycine-aspartic acid (cRGD) peptide reduces cytotoxicity, increases transfection efficiency in human anaplastic thyroid carcinoma ( $\mathrm{HTC} / 3)$ and malignant glioma (U87) cells [17, 18], and improves targeting ability $[17,19]$. Hence, the objective of this study was to elucidate whether PAMAM dendrimers could efficiently deliver short interfering RNAs (siRNAs) to SSCs.

Here, we for the first time applied PAMAM-cRGD dendrimers (G5-cRGD) to SSC transfection in comparison with a commercial reagent Lipofectamine 2000 (Lipo2000). We evaluated the physicochemical properties, cell toxicity, intracellular uptake, and gene silencing efficiency. We found that this vector was superior to Lipo2000 for delivery of siRNAs into SSCs. The outcome would contribute to studies on SSC biology and their potential applications to the clinics and animal production.

\section{Materials and methods \\ Animals}

ICR mice were purchased from the animal center of the Fourth Military Medical University, Xi'an, China. Testis samples were obtained from 6-day-old ICR mice. The experimental animals and procedures used in this study were approved by the Northwest A\&F University's Institutional Animal Care and Use Committee.

\section{Materials}

The poly(amidoamine) (PAMAM) dendrimer with an ethylenediamine core (generation 5 with 128 surface amino groups) was purchased from CYD (Weihai, China, CYD150A). Cyclic arginine-glycine-aspartic acid (cRGD) peptide was synthesized by GL Biochem Company (Shanghai, China, P170927-SY49331). 1-Ethyl-3-(3-dimethylaminopropyl) carbodiimide hydrochloride (EDC) and $N$-hydroxysuccinimide (NHS) were purchased from Sigma (St. Louis, MO, USA). The sequence of Cdk1 siRNA: GCCAGA TAGTGGCCATGAATT (21 bp), and the sequence of Cdk2 siRNA: CUUCUAUGCCUGAUUAUAATT (21 bp).
A scrambled siRNA duplex (21 bp) and FAM-labeled transfection scrambled siRNA (21 bp) were purchased from GenePharma (Shanghai, China). Lipofectamine 2000 reagent was purchased from Invitrogen (Carlsbad, CA, USA, 11668019). All chemicals and reagents were of analytical grade.

\section{Preparation of G5-cRGD}

$1.2 \mu \mathrm{g}$ of cRGD was dispersed in $10 \mathrm{ml}$ phosphate buffer saline (PBS; $\mathrm{pH}=7.4,10 \mathrm{mM}$ ); then, $1.5 \mathrm{mg}$ of EDC and $2.3 \mathrm{mg}$ of NHS were added. The mixture was stirred for $1 \mathrm{~h}$ at $4{ }^{\circ} \mathrm{C}$ in the dark, followed by the addition of 5.7 mg PAMAM (G5). After $12 \mathrm{~h}$ of reaction, the resulted PAMAM-cRGD (G5-cRGD) was added to a dialysis bag $(\mathrm{MwCO}=1000 \mathrm{D})$ and incubated in $500 \mathrm{ml}$ PBS $(\mathrm{pH}=$ $7.4,10 \mathrm{mM}$ ) for $12 \mathrm{~h}$ at $4{ }^{\circ} \mathrm{C}$ in the dark. The final product was dried by a freeze-dryer.

\section{Structural characterization of G5-cRGD}

The chemical structure of synthetic copolymers was characterized with Fourier transform infrared spectroscope (FTIR), specifically by VERTEX 70 FTIR Spectrometer (Bruker, Germany) in the range of 500-4000 $\mathrm{cm}^{-1}$. The samples were first mixed well with potassium bromide $(\mathrm{KBr})$ and then compressed into a tablet for analysis.

\section{Cell isolation}

The testis tissue was collected from 6-day-old ICR mouse pups. Testicular cells were obtained via a twostep enzymatic dissociation. In brief, testicular fragments were exposed to $1 \mathrm{mg} / \mathrm{ml}$ collagenase Type IV (Invitrogen, 17104019 ) for $5 \mathrm{~min}$ at $37^{\circ} \mathrm{C}$, followed by $0.25 \%$ trypsin-EDTA (Hyclone, Logan, UT, USA, SV30042.01) dissociation for $5 \mathrm{~min}$. Single-cell suspension was prepared in DMEM/F12 medium (Hyclone, SH30023.01) containing 1\% fetal bovine serum (FBS; Gibco, Grand Island, NY, USA, 10100147) and subjected to differential plating to remove the somatic cells [20]. To remove many peritubular myoid cells, the floating cells were transferred to a new plate after $0.5 \mathrm{~h}$ of incubation. Then, to remove Sertoli cells, the floating cells were transferred to a new plate after $2 \mathrm{~h}$ of incubation. Sertoli cells adhered to the plate and were maintained under the $37^{\circ} \mathrm{C}$ with $5 \% \mathrm{CO}_{2}$ of atmosphere. The floating cells which enriched with germ cell were cultured in $\mathrm{CO}_{2}$ incubator at $37^{\circ} \mathrm{C}$ overnight.

\section{Purification of undifferentiated spermatogonia by fluorescent-activated cell sorting (FACS)}

The uniform single-cell suspension after differential plating was used for cell sorting. After incubation with antibodies against E-cadherin (CDH1) for $30 \mathrm{~min}$, cells were stained for $20 \mathrm{~min}$ on ice with anti-rabbit-Alexa Fluor 
488. The cell fractions were washed with PBS and collected with a FACS Aria III cell sorter (BD Biosciences). The finally acquired $\mathrm{CDH}^{+}$germ cells were used for primary culture.

\section{Cell culture}

The C18-4 cell line was established from undifferentiated type A spermatogonia [21] and obtained from Dr. Zuping He at Shanghai Jiao Tong University, China. The cells were validated using various markers for mouse germ cells and SSCs [22]. The cells were cultured in DMEM/F12 containing 10\% FBS (BI, Israel, 04-121-1A) and $100 \mathrm{unit} / \mathrm{ml}$ penicillin and streptomycin (Invitrogen, 15140122 ) and maintained at $37^{\circ} \mathrm{C}$ in a humidified incubator $\left(5 \% \mathrm{CO}_{2}\right)$. The C18-4 cell line was characterized by using different SSC markers (CDH1 and Lin28) as shown in Additional file 1: Figure S2A.

The enriched SSCs were cultured in DMEM-F12 supplemented with 2\% FBS (Gibco), 5\% knockout serum replacement (KSR; Gibco, 10828028), $100 \mathrm{mM}$ nonessential amino acid solution (Invitrogen, 11140050), $100 \mathrm{unit} / \mathrm{ml}$ penicillin and streptomycin (Invitrogen, USA), $2 \mathrm{mM}$ L-glutamine (Invitrogen, 25030081), $1 \times$ MEM vitamin (Invitrogen, $11120052), 30 \mathrm{ng} / \mathrm{ml} \beta$-estradiol, $10 \mathrm{ng} / \mathrm{ml}$ Glial cell linederived neurotrophic factor (GDNF), and $10 \mathrm{ng} / \mathrm{ml} \mathrm{bFGF}$. The isolated Sertoli cells were validated using the specific marker (SOX9) as shown in Additional file 1: Figure S5. The cells were maintained in DMEM/F12 medium with 5\% FBS and cultured for three to four passages. To prepare feeder cell monolayers, Sertoli cells were mitotically inactivated by treatment with mitomycin $\mathrm{C}(10 \mathrm{mg} / \mathrm{ml})$ for $3 \mathrm{~h}$ followed by extensive washing in DPBS.

\section{Transmission electron microscope (TEM)}

G5-siRNA complexes (dendriplexes) and G5-cRGDsiRNA complexes (cRGD-dendriplexes) with the ratio of nitrogen atoms in the dendrimer to phosphorous atoms in the siRNA (N/P ratio) of 10 were measured by a transmission electron microscope (TEM; FEI, USA). The prepared specimens were diluted and added to a drop of the polyplex solution on a copper grid to dry naturally. The dried specimens were observed through a transmission electron microscope at an accelerating voltage of $80 \mathrm{kV}$.

\section{Preparation of nano-siRNA complexes and detection of compensation efficiency}

Nano-siRNA complexes containing dendriplexes and cRGD-dendriplexes were prepared by mixing scramble siRNA and cationic dendrimers in serum-free OptiMEM medium (Gibco, 31985062) at various N/P ratios from 0 to 40 at $37^{\circ} \mathrm{C}$ for $30 \mathrm{~min}$. Twenty microliters of the complexes containing the $0.1 \mu \mathrm{g}$ of siRNA solution was electrophoresed on the $3.5 \%$ agarose gel containing ethidium bromide at $120 \mathrm{~V}$ for $20 \mathrm{~min}$. A free naked siRNA was used as a negative control. The bands of siRNA were visualized under ultraviolet (UV) illumination condition.

\section{Zeta potential measurement}

Zeta potential of the nanoparticles and nano-siRNA complexes were measured using a Mastersizer ZEN3600 (Malvern Instruments Ltd., Malvern, UK). Nano-siRNA complexes were prepared at different $\mathrm{N} / \mathrm{P}$ ratios and then diluted with DPBS to $1.0 \mathrm{ml}$ volume before measure. Each sample was done in triplicate, and the average value was used. Reported values were calculated as the average of three independent experiments comprising 3 measurements for each.

\section{Immunocytochemistry}

Cells were seeded on 96-well plates and treated with nano-siRNA complexes, fixed with 4\% PFA for $20 \mathrm{~min}$ at room temperature, and permeabilized for $10 \mathrm{~min}$ using $0.1 \%$ Triton X-100 solution. Blocking was performed to suppress non-specific antibody binding by incubation with 10\% donkey serum (Abcam, Cambridge, UK, ab7475) for $2 \mathrm{~h}$. Subsequently, the cells were incubated with the primary antibodies against THY1 (1:200; Santa Cruz Biotechnology, CA, USA, SC-9163), CDH1 (1:200; Proteintech, Chicago, IL, USA, 20874-1-AP), PLZF (1: 100; Invitrogen, USA, PA5-29213), Lin28 (1:200; Abcam, Cambridge, UK, ab46020), or SOX9 (1:200; Santa Cruz Biotechnology, CA, USA, SC-166505) at $4{ }^{\circ} \mathrm{C}$ overnight. Afterwards, samples were incubated with the corresponding secondary antibody anti-mouse-Alexa Fluor 594 (1:200; Jackson Immunoresearch, 715-585-151), anti-rabbit-Alexa Fluor 488 (1:300; Jackson Immunoresearch, 711-545-152), or anti-rabbit-Alexa Fluor 594 (1: 300; Jackson Immunoresearch, 711-585-152) at room temperature for $1 \mathrm{~h}$ and counterstained with Hoechst 33342 (Beyotime Institute of Bio-technology, C1022). Negative controls were incubated with 10\% donkey serum without the primary antibody. Finally, fluorescent images were acquired with an Olympus IX71 (Tokyo, Japan) inverted fluorescence microscope camera.

\section{Cytotoxicity assay}

Cell viability was determined by Cell Counting Kit- 8 (CCK-8) assay (Beyotime Institute of Biotechnology, Jiangsu, China, C0042) and MTT assay (Beyotime Institute of Biotechnology, Jiangsu, China, C0009). The cells were prepared and dispersed in 96-well cell culture plates at a cellular density of $5.0 \times 10^{3}$ cells/well and cultured for $24 \mathrm{~h}$. In order to detect the toxicity of different concentrations of nanoparticle (NPs), the cells were treated with G5 and G5-cRGD NPs, respectively, at various concentrations $(10,20,30,40$, and $60 \mu \mathrm{g} / \mathrm{ml})$ for 24 
$\mathrm{h}$ at $37^{\circ} \mathrm{C}$. In addition, to detect the toxicity of different $\mathrm{N} / \mathrm{P}$ ratios of nano-siRNA complexes, the cells were transfected with dendriplexes and cRGD-dendriplexes, respectively, at various N/P ratios for $48 \mathrm{~h}$, followed by incubation with Opti-MEM medium only for $6 \mathrm{~h}$. Finally, $10 \mu \mathrm{l}$ of CCK-8 solution in DMEM was added to each well and incubated at $37^{\circ} \mathrm{C}$ for $2 \mathrm{~h}$. The optical density of each well was measured at $450 \mathrm{~nm}$ with a microplate reader. For the MTT assay, $10 \mu \mathrm{l}$ of MTT $(5 \mathrm{mg} / \mathrm{ml})$ reagent was added to each well and incubated for $4 \mathrm{~h}$. Formazan solvent $(100 \mu \mathrm{l})$ was added to each well until all crystals dissolved. The absorbance was measured at 570 $\mathrm{nm}$ by a microplate reader. Results were calculated as the absorbance of treated cells relative to untreated controls. At least three independent experiments were performed.

\section{Cell transfection}

Before transfection, $1.5 \times 10^{5}$ cells were seeded on plates (6-well) with fresh complete DMEM medium. The commercial Lipofectamine ${ }^{\circ} 2000$ reagent (Lipo2000) was used according to the manufacturer's instruction. Dendriplexes and cRGD-dendriplexes were assembled at N/P ratios ranging from 1 to 15 in serum-free Opti-MEM medium at $37^{\circ} \mathrm{C}$ for $30 \mathrm{~min}$. The final siRNA concentration was adjusted to 100 nM with complementing Opti-MEM medium. After 6 $\mathrm{h}$ of incubation, the transfection mixture was replaced with the complete medium and maintained for further incubation up to $48 \mathrm{~h}$. A free naked siRNA was used as a negative control. In order to facilitate the observation of cellular internalization, we used FAMlabeled siRNA for transfection. The cellular internalization was observed under a REVOLUTION WD confocal laser scanning microscope (CLSM; Andor, UK) with a $100 \times$ oil immersion lens.

\section{Flow cytometry}

To determine the siRNA delivery efficiency, cells were transfected with FAM-labeled siRNA at $100 \mathrm{nM}$. The cells were seeded on 6-well culture plates for $24 \mathrm{~h}$, and the medium was then replaced with the control (OptiMEM), free siRNA, dendriplexes, and cRGDdendriplexes at various N/P ratios, respectively. After $6 \mathrm{~h}$ of incubation in serum-free Opti-MEM medium, the cells were trypsinized and were re-suspended in $100 \mu \mathrm{l}$ of cold PBS. Naked siRNA was used as a negative control. A total of 10,000 events were collected for each measurement. The transfection efficiency was calculated by the percentage of $\mathrm{GFP}^{+}$cells. FlowJo software was used to analyze the data and quantify the mean fluorescence intensity (MFI) per cell. Each assay was performed in triplicates.

\section{Uptake pathway studies by inhibiting endocytosis}

To inhibit the endocytic pathways, cells were treated with sodium azide $\left(\mathrm{NaN}_{3}\right)$ and under low-temperature condition, respectively. The cells were pre-incubated with $\mathrm{NaN}_{3}(40 \mu \mathrm{M})$ for $30 \mathrm{~min}$, followed by incubation at $37^{\circ} \mathrm{C}$ with cRGD-dendriplexes (N/P 10:1) for $2 \mathrm{~h}$. Later, blocking experiments were carried out by incubating cells with cRGD-dendriplexes at $4{ }^{\circ} \mathrm{C}$ for $1 \mathrm{~h}$. Finally, the samples were washed three times with $\mathrm{PBS}$, and fluorescent micrographs were acquired with an Olympus IX71 (Tokyo, Japan) inverted fluorescence microscope camera.

\section{Endosomal escape}

Cells were seeded at a density of $5 \times 10^{4}$ cells/ confocal dish and incubated for $48 \mathrm{~h}$. The cells were incubated with dendriplexes or cRGD-dendriplexes (N/P 10:1) for $6,12,24$, and $36 \mathrm{~h}$, respectively. Subsequently, the cells were treated with Lyso-Tracker Red (Beyotime Institute of Bio-technology, C1046) for $1 \mathrm{~h}$ and stained with Hoechst 33342 (Beyotime Institute of Bio-technology, C1022) for $20 \mathrm{~min}$ at $37^{\circ} \mathrm{C}$. Finally, fresh culture medium without phenol red was added. The samples were captured by REVOLUTION WD CLSM (Andor) with a $100 \times$ oil immersion lens. Quantitative colocalization showed the proportion of the FAM-labeled siRNA that colocalize with Lyostracker Red (yellow puncta) to the FAM-labeled siRNA (green puncta) per cell. Endosomal escape experiments were repeated three times and counted 100 cells.

\section{Quantification of germ cell colonies}

Primary SSC-derived colonies were assessed by the result described by Kanatsu-Shinohara et al. with a minor modification [20]. CDH1-FACS sorted germ cells were seeded at $2 \times 10^{4}$ cell/well in 48 -well dishes on feeder layers (Sertoli cells). To count colonies, the cells were cultured for 5 days after transfection with nano-siRNA complexes for $12 \mathrm{~h}$. The morphology of cell colonies was observed by inverted microscope (Olympus IX71, Tokyo, Japan). Next, we calculated the mean number of colonies (a cluster consists of more than 5 cells) per square centimeter. Experiments were repeated three times.

\section{Proliferation assay}

To assess proliferation, the cells were seeded on 96-well plates. After transfection, cell proliferation was detected using an EdU Cell Proliferation Assay Kit (Ribobio, Guangzhou, China, C10310-3). The EdU assay was performed 2 or 7 days after transfection in SSC line and primary SSCs, respectively. In brief, cells were maintained in complete medium with $50 \mu \mathrm{M}$ of EdU for 2 to $4 \mathrm{~h}$. After fixation with $4 \%$ paraformaldehyde (PFA) for 30 min at room temperature, the cells were neutralized by 
glycine $(2 \mathrm{mg} / \mathrm{ml})$. After washing, the cells were permeabilized with $0.5 \%$ Triton X-100 solution. The EdU staining was performed. Subsequently, cells were stained with Hoechst 33342 and evaluated under a fluorescent microscope (Olympus, Tokyo, Japan). Cell proliferation activity was determined by defining the proliferation index: the ratio of EdU-positive cells to total number of cells. Experiments were repeated three times, and each time we randomly selected 5 fields for statistics. A total of 500 cells were counted.

\section{Cell cycle assay}

Cell cycle progression was examined by flow cytometer using 4',6-diamidino-2-phenylindole (DAPI) staining. Cells were seeded in six-well culture plates. Cell cycle assay was performed 7 days after transfection in primary SSCs. The cells were stained with CDH1 using antirabbit-Alexa Fluor 488. Subsequently, cell cycle was monitored by using DAPI staining of nuclei and subjected to flow cytometry analysis [23]. All measurements analysis was carried out using ModFit (Verity Software, Topsham, ME, USA) data analysis software. Experiments were performed independently at least three times.

\section{TUNEL assay}

To detect cell apoptosis, the cells were seeded on 96well plates. After transfection, cell apoptosis was detected using a TUNEL BrightRed Apoptosis Detection Kit (Vazyme, Jiangsu, China, A113-01). The TUNEL assay was performed 7 days after transfection in primary SSCs, following the manufacturer's instructions. In brief, cells were fixed in $4 \%$ paraformaldehyde and permeabilized for $10 \mathrm{~min}$ using $0.1 \%$ Triton-X100 solution at room temperature. Then, the cells were incubated with $50 \mu \mathrm{TdT}$ incubation buffer at $37^{\circ} \mathrm{C}$ for $1 \mathrm{~h}$ in darkness. Finally, cells were stained with DAPI and evaluated under a fluorescent microscope (Olympus, Tokyo, Japan). The ratio of the TUNEL-positive cells (red fluorescence) to the CDH1-positive cells (green fluorescence) indicated the primary SSC apoptosis. Experiments were repeated three times, and each time we randomly selected 5 fields for statistics.

\section{RNA extraction and quantitative real-time PCR analysis}

RNA was extracted from the cells with Trizol reagent (Takara, 9109) according to the manufacturer's protocol. For each sample, $1 \mu \mathrm{g}$ of total RNA was subjected to reverse transcription using Transcriptor First Strand cDNA Synthesis Kit (Roche, Mannheim, Germany, 04897030001). FastStart Universal SYBR Green Master (Roche, 38697500) was used for Real-time PCR using an IQ5 (Bio-Rad). $\beta$-actin and GAPDH were used as the internal reference, and the data were analyzed using the $2^{-\Delta \Delta \mathrm{CT}}$ method [24].

\section{Western blot}

Proteins were extracted using RIPA buffer (Solarbio, Beijing, China, R0020) according to the manufacturer's protocol. The concentration of protein was measured by BCA kit (Takara, Japan, AI90451A). Thirty micrograms of total proteins from each sample were separated by polyacrylamide gel electrophoresis and transferred onto poly-vinylidene fluoride (PVDF) membranes (Millipore, Billerica, MA, USA). The blottransferred membranes were blocked with $5 \%$ fat-free dry milk for $2 \mathrm{~h}$ and incubated with primary antibodies: mouse anti-PCNA (1:500; Santa Cruz Biotechnology, PC10), mouse anti-CDK1 (1:500; Santa Cruz Biotechnology, AN21.2), mouse anti-CDK2 (1:500; Santa Cruz Biotechnology, D-12), and mouse anti beta-ACTIN (1:2000; CWBIO, Beijing, China, CW0096) on a shaker at $4{ }^{\circ} \mathrm{C}$ overnight, followed by incubation with horseradish peroxidase (HRP)-conjugated anti-mouse IgG (1:2000; Millipore, AP192P). Protein bands were visualized and captured by a BioRad Chemidoc XRS using a Western Bright ECL Kit (Bio-Rad, Berkeley, CA, USA). The protein bands were hand-drawn for 3 times and calculated the average intensity by Image-Pro Plus. The ratio of the target protein to the corresponding intensity value of $\beta$-actin was obtained for analysis. Experiments were repeated three times.

\section{Statistical analysis}

The data obtained are shown as mean \pm standard deviation (SD). One-way ANOVA or Student's $t$ test was performed to determine the differences of the data. A value of $P<0.05$ was considered statistically significant.

\section{Results}

Synthesis and characterization of G5-CRGD and CRGDdendriplexes

Based on the previous report [25], the cRGD was modified on the surface of the fifth generation of PAMAM dendrimers (G5). The structural composition of PAMAM-cRGD dendrimers (G5-cRGD) was confirmed by FTIR. The weak characteristic peak of sulfhydryl group $(-\mathrm{SH})$ appeared at $2500 \mathrm{~cm}^{-1}$ indicates the successfully modification of $\mathrm{cRGD}$ on the surface of PAMAM (Additional file 1: Figure S1).

The size and morphology of nanoparticles were determined by TEM. The G5 nanoparticles were in irregular shapes (Fig. 1a). Upon addition of siRNA to G5 or G5-cRGD, these nano-siRNA complexes selfassembled into spherical structures with the average particle sizes of 71.37 and $80.86 \mathrm{~nm}$, respectively (Fig. 1a). Interestingly, the G5-cRGD-siRNA complexes (cRGD-dendriplexes) were more uniform than G5siRNA complexes (dendriplexes). 

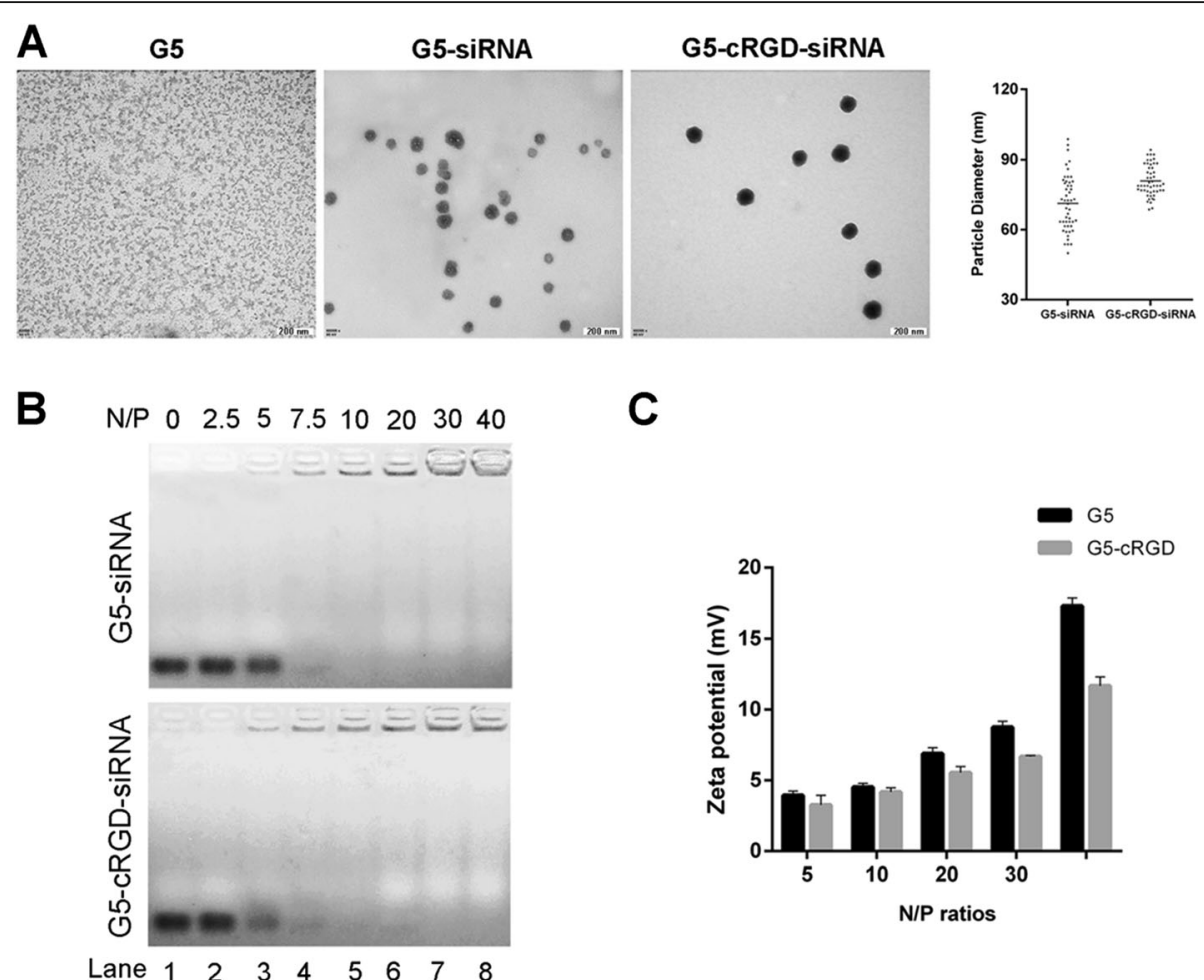

C

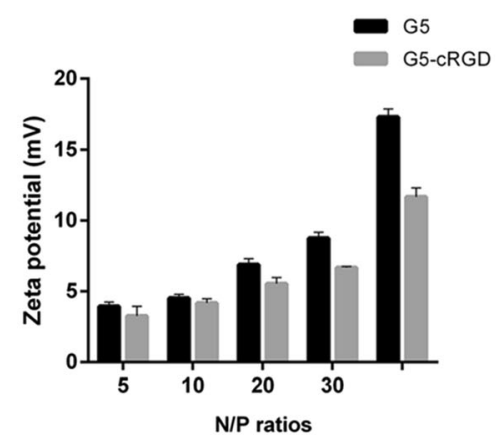

Fig. 1 Physicochemical characterization of nano-siRNA complexes. a TEM images of G5 and the complexes of G5-siRNA (dendriplexes) and G5CRGD-siRNA (CRGD-dendriplexes) at the N/P ratio of 10. Scale bar is $100 \mathrm{~nm}$. Particle size distribution of nano-siRNA complexes obtained by TEM images. Fifty nanoparticles were counted. b Representative images of gel retardation assay for G5-siRNA and G5-cRGD-siRNA at different N/P ratios. Lane 1: naked siRNA, lanes 2-8: nano-siRNA complexes (N/P ratios 2.5:1, 5:1, 7.5:1, 10:1, 20:1, 30:1 and 40:1). c Zeta potentials of nano-siRNA complexes at different N/P ratio

To determine the load efficiency of siRNA in the nano-vectors, the agarose gel retardation assay was performed. With the increase of N/P ratios, siRNA bands gradually decreased and completely disappeared when the N/P ratio was higher than 10 in either dendriplexes or cRGD-dendriplexes (Fig. 1b), indicating that G5 and G5-cRGD are able to efficiently bind and load siRNAs. As shown in Fig. 1c, G5 nanoparticle exhibited positive zeta potential values around $+17.30 \mathrm{mV}$, while G5 modification with cRGD could partially reduce the cationic charge. Zeta potentials of the nano-siRNA complexes gradually increased with increasing N/P ratio.

\section{Cytotoxicity assay of G5-CRGD in the C18-4 undifferentiated spermatogonial cell line}

The mouse SSC line C18-4 cells were characterized by using different SSC markers. Immunocytochemical staining revealed that $\mathrm{CDH} 1$ [26] and Lin28 [27] were expressed in C18-4 cells (Additional file 1: Figure S2A). Subsequently, the cytotoxicity of G5, G5-cRGD, dendriplexes, and cRGD-dendriplexes was evaluated in an SSC line by CCK- 8 assay. Cell viability decreased with the increase of the concentration of nanoparticles. The viability in G5-cRGD group was higher than that in G5
(Fig. 2a). The viability also reduced with the increase of charge ratio (Fig. 2b). It was higher in the G5-cRGD group than in the G5 group in all the ratios tested. MTT assay was used to corroborate these observations (Additional file 1: Figure S2B and C). Importantly, cell viability in G5-cRGD group was over 90\% with a 10:1 ratio, which represented a good biocompatibility. Cell viability in the positive control, a commercial reagent Lipo2000, was $60.31 \%$ (Fig. 2b). These results demonstrate that conjugation of G5 with cRGD leads to less cytotoxicity.

\section{Transfection efficiency and uptake pathway of G5-cRGD} in the C18-4 undifferentiated spermatogonial cell line Live cell confocal imaging was performed to visualize the intracellular distribution of nano-siRNA complexes. The fluorescence was localized in the cytoplasm when cells were treated with dendriplexes or cRGDdendriplexes (Fig. 3a), indicating that siRNAs are effectively delivered into SSCs via G5 and G5-cRGD.

Higher N/P ratios are essential to break the cell membrane barrier and improve transfection efficiency, which is, in turn, accompanied by damages to cell membrane integrity. The transfection efficiency increased with the increase of N/P ratio (Fig. 3b). The percentage of FAM- 

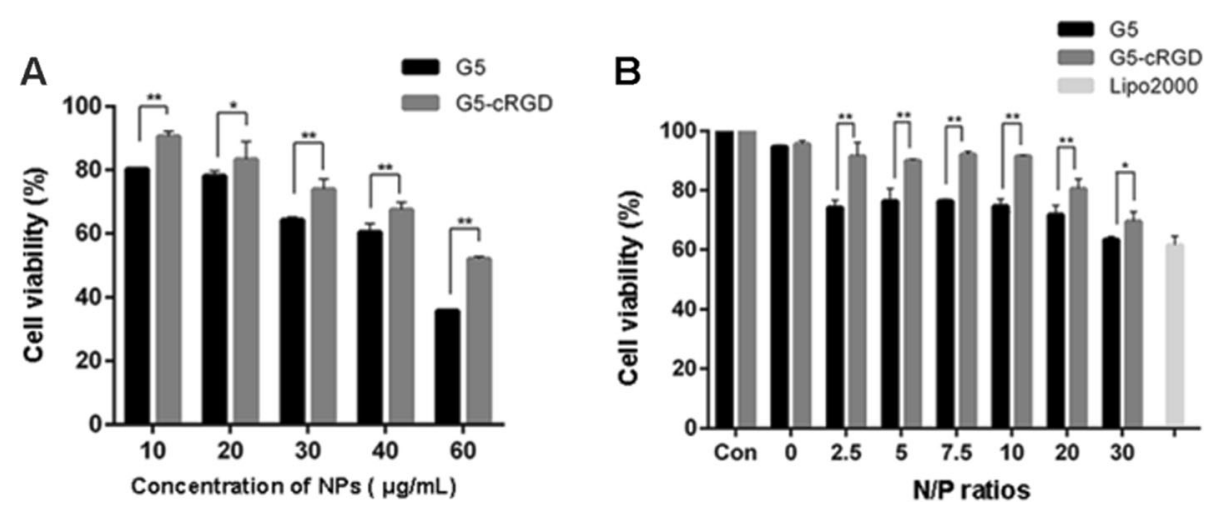

Fig. 2 Toxicity profile of the G5-CRGD-mediated delivery system. a The viability of the SSC line incubated with G5 and G5-CRGD nanoparticles at various concentrations by CCK-8 assay. $\mathbf{b}$ The viability of the SSC line transfected with G5-siRNA and G5-CRGD-siRNA complexes at different N/P ratios for $24 \mathrm{~h}$, as evaluated by CCK-8 assay. The final siRNA concentration of each sample was $100 \mathrm{nM}$. Lipo2000 was used as a positive control. Statistical significance was determined by applying the Student's $t$ test. Data are presented as mean \pm standard deviation $(S D, n=3)$. ${ }^{*} p<0.05,{ }^{* *} p<0.01$

positive cells was more than $80 \%$ when the $\mathrm{N} / \mathrm{P}$ ratio was 5 , and reached up to $90 \%$ when N/P was 10 . Further increase N/P ratio did not yield higher transfection efficiency. Taken together the data from the gel retardation assay and cytotoxicity test (Figs. $1 \mathrm{~b}$ and $2 \mathrm{~b}$ ), we decided to use the N/P ratio of 10 in the following experiments. When the N/P ratio was 10 , transfection efficiency in G5-cRGD group $(89.73 \pm 3.34 \%)$ was similar with in Lipo2000 (92.84 $\pm 1.95 \%)$, in G5 $(85.33 \pm 1.76 \%)$ was less than in Lipo2000 (Fig. 3c, d). In addition, flow cytometry assay showed that mean fluorescence intensity (MFI) in G5-cRGD was significantly stronger than that in G5 group (Fig. 3e). It has been reported that higher MFI could lead to higher targeted delivery efficiency [28].

We determined by qualitative analysis on immunofluorescent images whether uptake depends on active translocation. The fluorescence in G5-cRGD-siRNA group was stronger than in G5 group (Additional file 1: Figure $\mathrm{S} 3 \mathrm{C}$ and $\mathrm{F})$. Sodium azide $\left(\mathrm{NaN}_{3}\right)$, an oxidative phosphorylation inhibitor, is able to abolish ATP production within the membrane and prohibit endocytosis [29]. Interestingly, the fluorescence intensity decreased in $\mathrm{NaN}_{3}$ treatment although it was still discernable (Additional file 1: Figure S3I). Moreover, the cellular uptake of cRGD-dendriplexes significantly reduced at $4{ }^{\circ} \mathrm{C}$ in comparison with the control at $37^{\circ} \mathrm{C}$ (Additional file 1: Figure S3L).

\section{Endosomal escaping of siRNA in the C18-4 undifferentiated spermatogonial cell line}

Efficient uptake of siRNA is the first step for gene silencing, and the successful escape of siRNA from endosomes into the cytoplasm is equally important [13]. To detect the endosomal escaping, we stained endosome/lysosomes with Lyso-Tracker Red. In the confocal images, yellow fluorescence represented the colocalization of
FAM-siRNA (green) with late endosomes/lysosomes (red). The yellow fluorescence revealed that cRGDdendriplexes distributed in endosomes/lysosome at $6 \mathrm{~h}$ post transfection, and more yellow spots localized in the cytoplasm at $12 \mathrm{~h}$. After $24 \mathrm{~h}$, a small number of green spots separated from Lyso-tracker Red, indicating that siRNA began to escape from the endosomes (Additional file 1: Figure S4A). More green fluorescence was separated from the red fluorescence at $36 \mathrm{~h}$ (Additional file 1: Figure S4B). The co-localization ratio significantly decreased to $47.20 \%$ in the cRGD-dendriplexes group, while $66.81 \%$ in the dendriplexes group at $36 \mathrm{~h}$ (Additional file 1: Figure S4C).

\section{Functional siRNA delivery in the C18-4 undifferentiated spermatogonial cell line}

Cyclin-dependent kinases (Cdks) 1 and 2 are involved in the regulation of cell cycle progression. To assess the nanoparticle delivery system, SSCs were treated with cRGD nanoparticles carrying siRNA against Cdk1 and Cdk2. We detected whether knockdown of Cdks by G5-cRGD-mediated siRNA delivery is associated with disturbances in cell cycle progression. As shown in Fig. 4a, b, expression of $C d k 1$ and $C d k 2$ was significantly lower in knockdown groups than that in NC groups, suggesting that both Cdk1 and Cdk2 siRNAs worked in G5, G5-cRGD, and Lipo2000 approaches. Moreover, the expression of CDK1 and CDK2 in KD- $(C d k 1+C d k 2)$ group was significantly decreased at the protein level when G5-cRGD or Lipo2000 was used as a carrier (Fig. 4d, e). In line with $C d k s$ expression, cell viability in G5-cRGD was significantly lower than that in G5 vector (Fig. 4c). Importantly, expression of proliferating cell nuclear antigen (PCNA) in G5-cRGD was lower than that in G5 cargo with siRNAs (Fig. 4d, e). Subsequently, EdU 


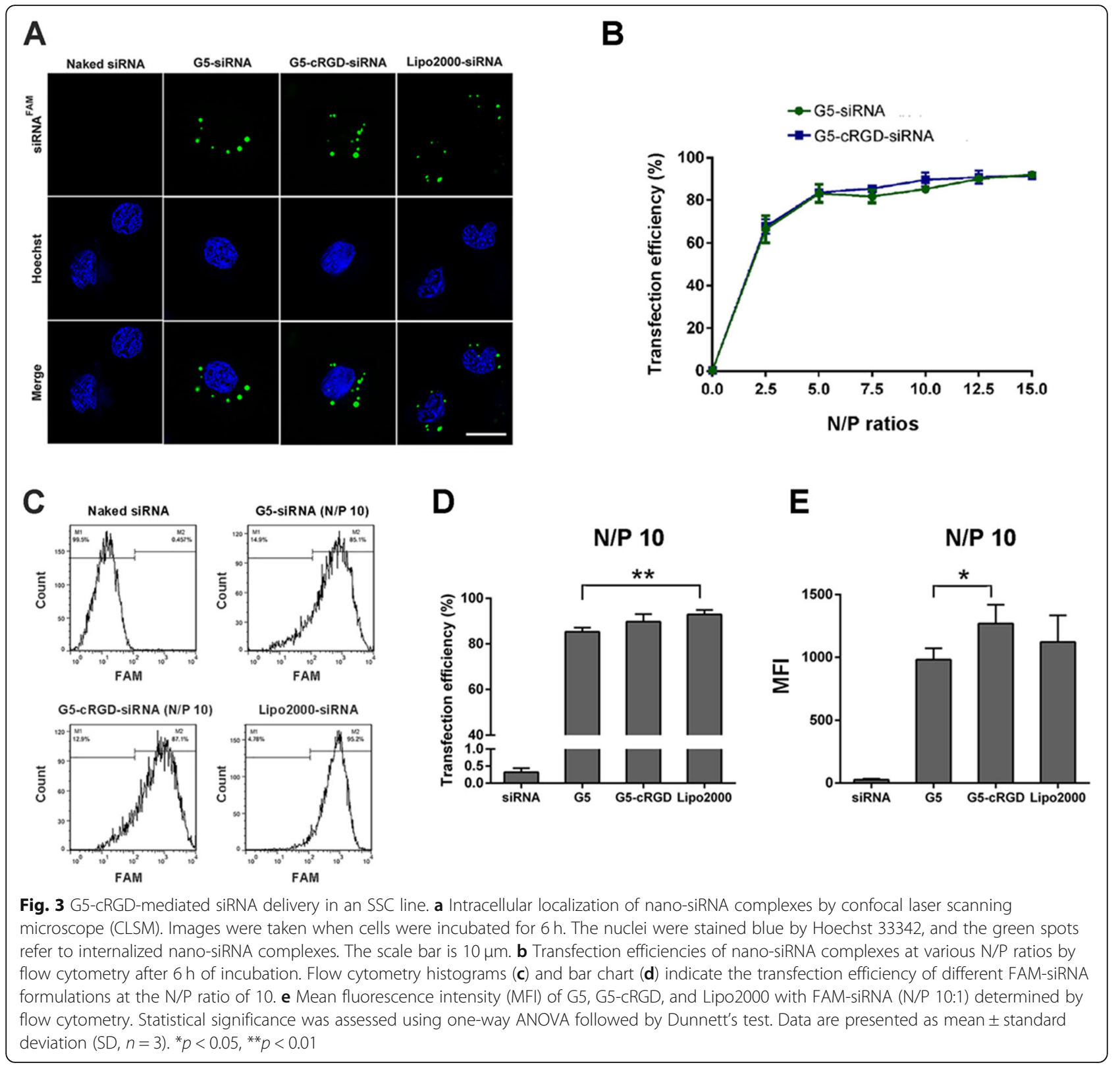

assay further showed that delivery of siRNAs with G5cRGD led to a significant decrease of EdU-positive cells (Fig. 4f, g).

\section{Transfection efficiency of G5-CRGD in primary SSCs}

Analysis of FACS-sorted cells showed that E-cadherin (CDH1)-positive cells reached 95\% (Fig. 5a). Immunocytofluorescence analysis showed that almost all colonies were positive for $\mathrm{CDH} 1$, promyelocytic leukemia zincfinger (PLZF) [30], and lin-28 homolog A (Lin28), indicating the SSC origin (Fig. 5b).

Subsequently, we investigated the potential application of G5-cRGD for siRNA transfection in primary SSCs. First, localization of FAM-labeled siRNA was examined by confocal microscopy. CDH1-FACS-sorted germ cells were stained for Thymocyte antigen 1 (THY1; a SSC marker). As shown in Fig. 6a, labeled-siRNAs were observed in the cytoplasm of THY1-positive cells. There were $28.28 \pm 3.33 \%$ THY1-positive cells displaying FAM fluorescence in the G5 group, while the percentage increased to $50.92 \pm 3.17 \%$ in the G5-cRGD group. More importantly, the transfection efficiency in G5-cRGD was also prominently improved in comparison with Lipo2000 (36.31 $\pm 4.07 \%$; Fig. 6b, c).

\section{Functional siRNA delivery in primary SSCs}

Finally, knockdown of both $C d k 1$ and $C d k 2$ was examined in the primary SSCs. Compared with the NC group, 


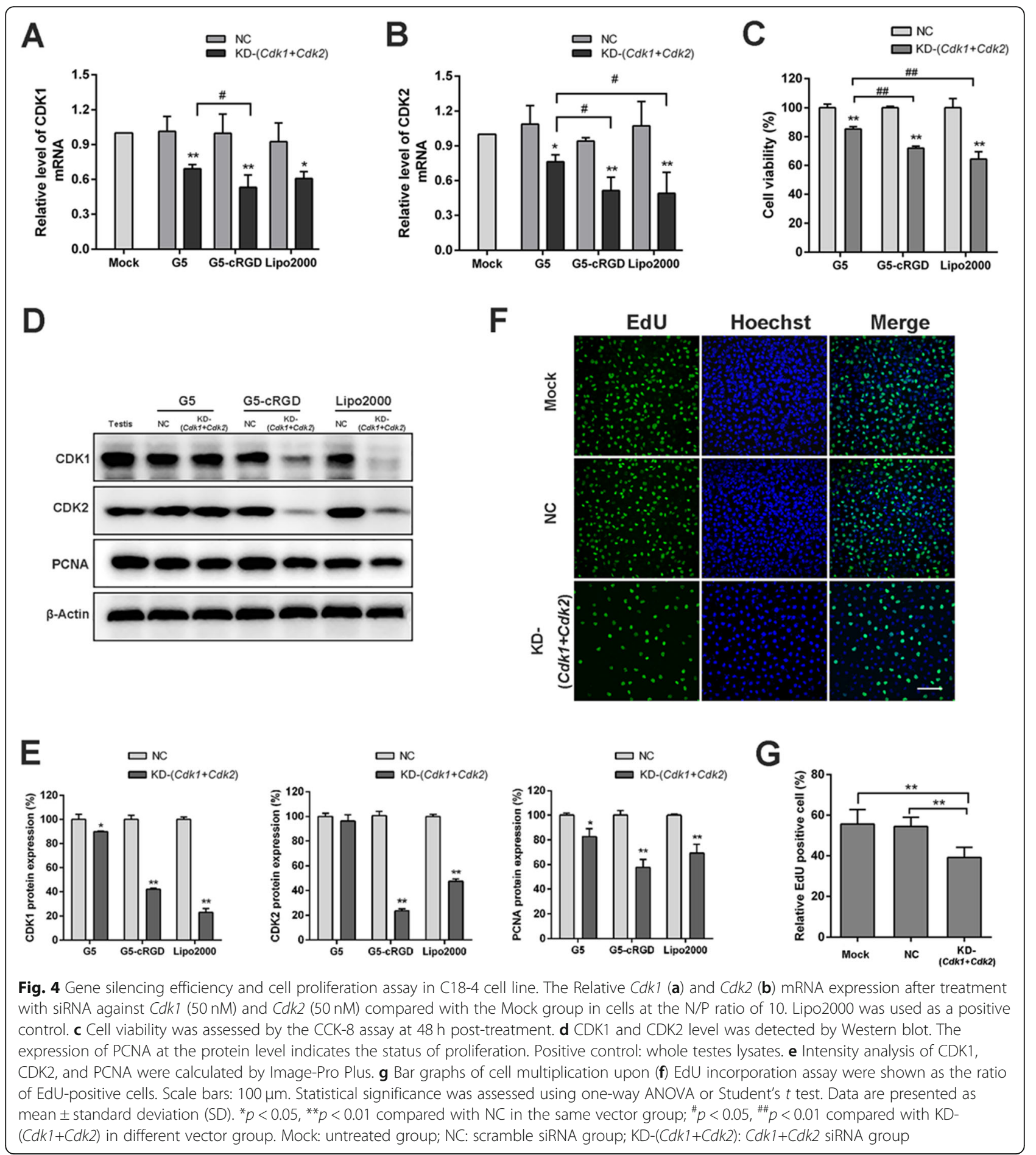

delivery of siRNAs by G5-cRGD nanoparticles resulted in significant suppression of Cdks expression (Fig. 6d, e). We further quantified the SSC-derived colonies as an index for SSC proliferative activity. The average number of colonies in siRNA groups was significantly lower than those in NC groups when G5-cRGD or Lipo2000 was used as carriers (Fig. 7a). The significant reduction was observed in the G5-cRGD group (Fig. 7a, b). The Lipo2000-mediated NC group significantly reduced the number of colonies, while the G5-cRGD-mediated NC group was comparable to the Mock group, indicating G5-cRGD is less cytotoxic to SSCs. Subsequently, EdU assay showed that $31.84 \pm 1.65 \%$ of the cells were positive for EdU staining in G5-cRGD group, while $57.10 \pm$ 

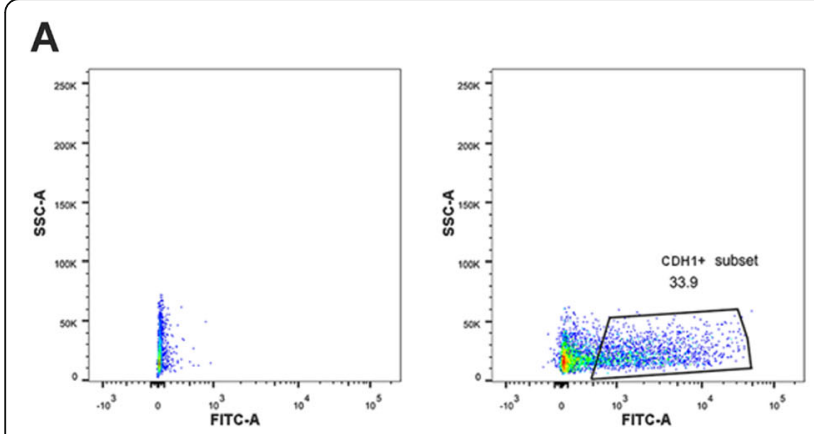

B
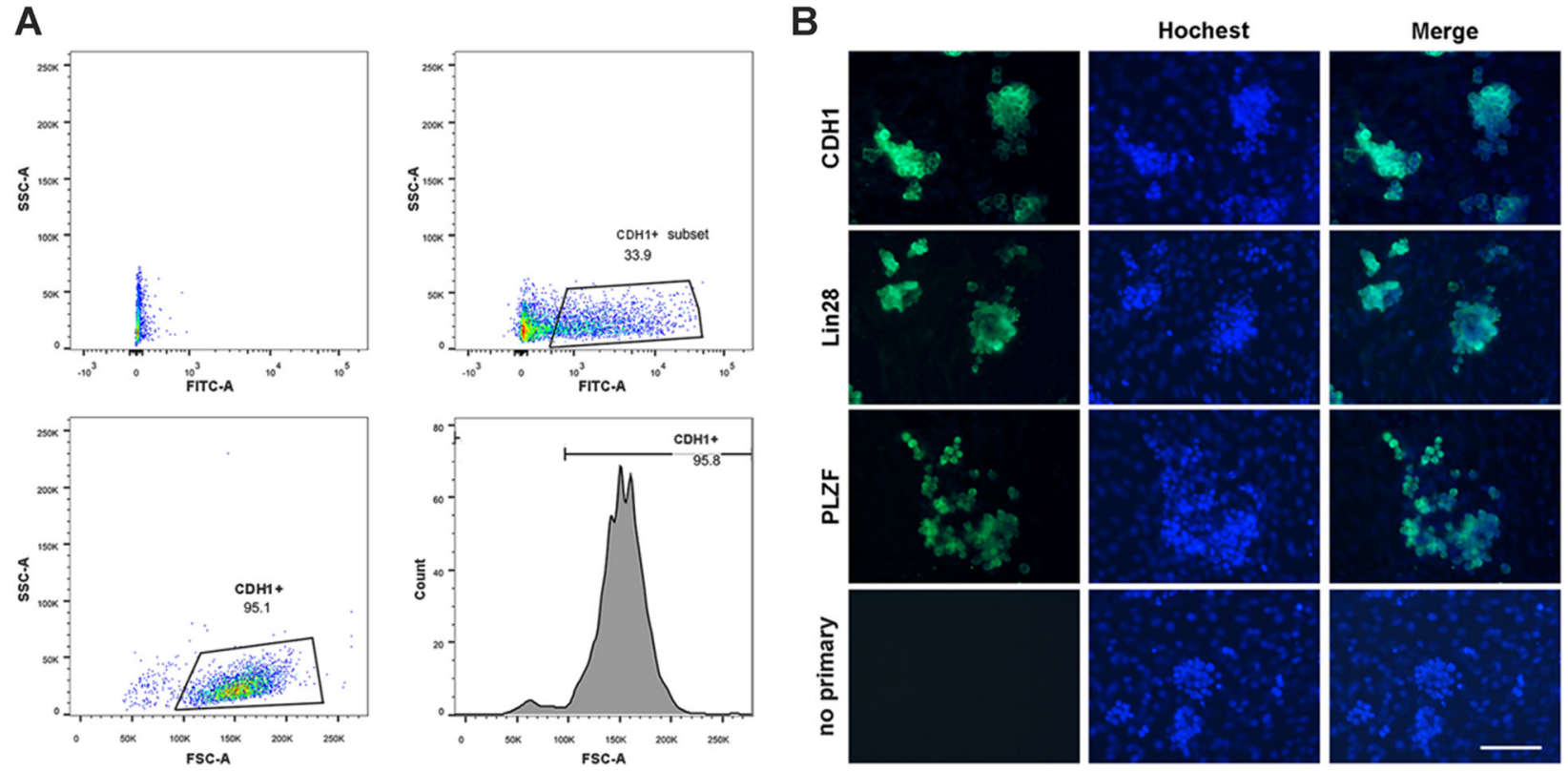

Fig. 5 Purification and characterization of primary SSCS. a Flow cytometry data to illustrate the gating strategy for FACS purification of CDH1 ${ }^{+}$ germ cells. $\mathbf{b}$ Immunocytochemical staining of SSC colonies on Sertoli cell feeder layer after 14 days of culture. The fluorescence staining is performed on CDH1 FACS sorted cells following differential plating. Expression of CDH1, Lin28, and PLZF in SSC colonies was showed in green fluorescence. Negative (no primary) control: omission of primary antibody. The nuclei (blue) were stained with Hoechst 33342 . Scale bar: $100 \mu \mathrm{m}$

$1.42 \%$ and $51.53 \pm 3.12 \% \mathrm{EdU}^{+}$cells in the Mock and NC groups, respectively (Fig. 7c, d). Next, we investigated the cell cycle progression by DAPI/FACS. As shown in Fig. 7e, f, delivery of $C d k 1$ and $C d k 2$ siRNAs with G5cRGD led to a significant increase in percentages of $\mathrm{S}$ and G2/M cell phases compared with the Mock and NC groups. As cell cycle arrest may cause apoptosis, we further explored the effect of CDK1 and CDK2 knockdown on apoptosis by TUNEL. The results demonstrated that 7 days after transfection, the TUNEL-positive cell rates in Mock, NC, and $\mathrm{KD}-(C d k 1+C d k 2)$ groups were $12.38 \pm 0.83 \%, 12.66 \pm 0.23 \%, 14.53 \pm 1.89 \%$, respectively (Fig. 7g, h). Compared with the Mock and NC groups, there was no significant difference in the KD$(C d k 1+C d k 2)$ group on apoptosis. In addition, no visible change in cell morphology was observed in cells transfected with scrambled siRNA/G5-cRGD, excluding the possibility of toxic effects of G5-cRGD. Therefore, G5cRGD exhibits low cytotoxicity and high efficiency for functional delivery of siRNAs in the primary SSCs.

\section{Discussion}

PAMAM dendrimers are the extensively studied nonviral vectors for siRNA delivery [13, 31]. SSCs are refractory to transfection, prompting us to probe whether PAMAM dendrimers can be used to efficiently deliver siRNAs to SSCs. Here, we demonstrated that G5-cRGD improved transfection efficiency and gene silencing in male germline stem cells.
Previous studies showed that the delivery efficiency of nanocomplexes was determined by numerous factors including generation, gene binding capacity, size, and toxicity [32]. It has been reported that lower generation dendrimers $(G<4)$ have an open structure, but dendrimers $(G \geq 4)$ possess a densely packed surface in higher generation [33]. Higher generation dendrimers are associated with more toxicity. The fifth generation of PAMAM dendrimers possesses lower toxicity and higher delivery capacity [34]. Their particle size is an important factor for cellular entry. A previous study reported that the optimal particle size for gene delivery via non-targeting cationic vectorDNA complexes is $70-90 \mathrm{~nm}$ [35]. In the present study, the mean diameter of dendriplexes was $70 \mathrm{~nm}$. Meanwhile, cellular toxicity is another challenge for application in biological system. The cationic surface of dendrimer is inevitably adverse to the stability of cell membranes that are negatively charged [36]. Fortunately, several studies have revealed that the overall toxicity can be mitigated by surface modification with agents such as cRGD, PEG, and cyclodextrins [17, 37, 38]. Therefore, we modified G5 surfaces with cRGD and synthesized G5-cRGD nanocarrier. We found that this modification led to a significant reduction in cytotoxicity. One possible explanation is that cRGD could partially reduce the terminal cationic density. Taken together, these observations suggest that G5cRGD may be a more efficient delivery system. 


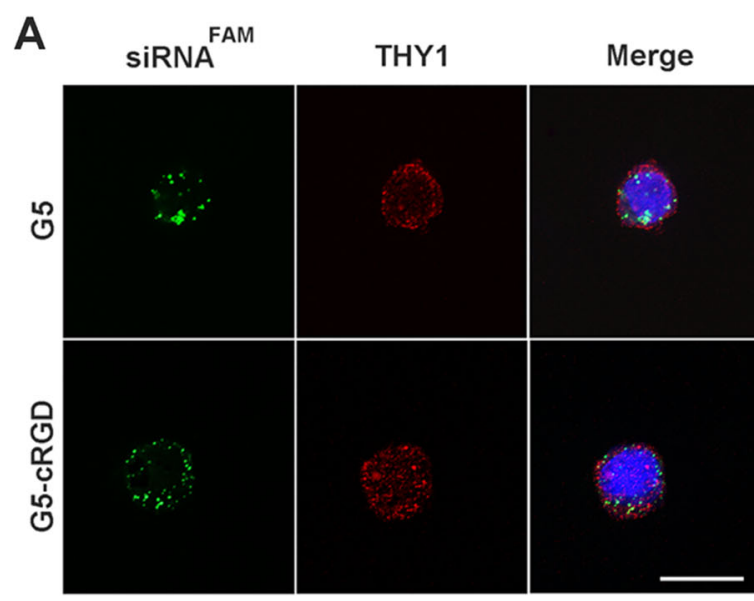

\section{C}

B

B SiRNA ${ }^{\text {FAM }}$ THY1 Merge
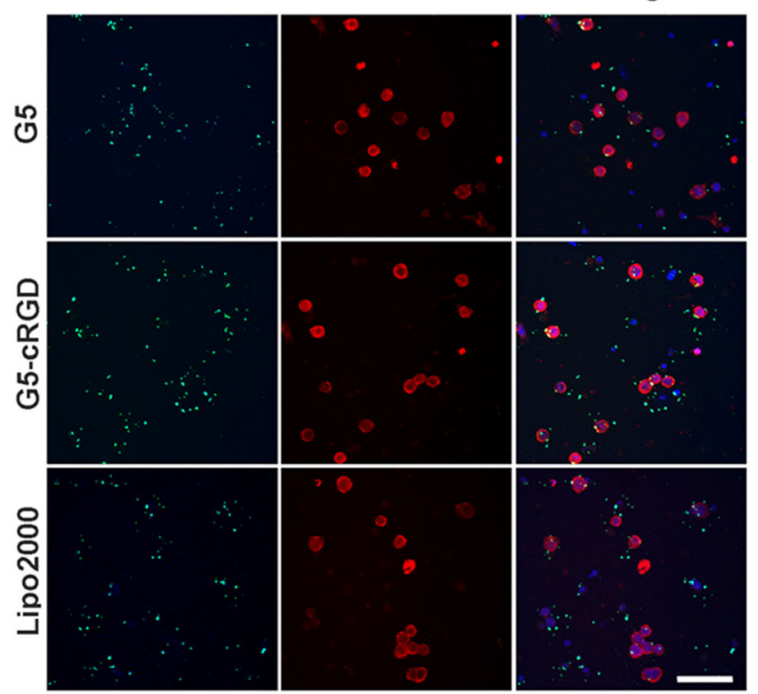

Fig. 6 G5-CRGD-mediated siRNA delivery in primary SSCs. a Localization of FAM-siRNA with G5 or G5-cRGD as carries was examined by CLSM 12 $\mathrm{h}$ after the transfection. Labeled siRNA was located in the THY1-positive cell cytoplasm. Red: THY1 staining used to mark SSCs; green: FAM-labeled siRNA; blue: Hoechst 33342 used to stain nuclei. Scale bars: $10 \mu \mathrm{m}$. b Fluorescent photographs were prepared $12 \mathrm{~h}$ after transfection with different FAM-siRNA formulations. Scale bars: $50 \mu \mathrm{m}$. c Percentages of FAM-positive cells among the THY1-positive cells were determined from 20 randomly selected regions by three independent experiments. Suppression of Cdk1 (d) and Cdk2 (e) using the G5-cRGD delivery vector was examined in primary SSCs at the mRNA level. Statistical significance was assessed using one-way ANOVA followed by Dunnett's test. Data are presented as mean \pm standard deviation (SD). ${ }^{*} p<0.05,{ }^{* *} p<0.01$. Mock: untreated group; NC: scramble siRNA group; KD-(Cdk1+Cdk2): Cdk1+Cdk2 siRNA group

Previous studies reported that the efficiency of gene silencing was siRNA-concentration-dependent, and reached a plateau at more than $100 \mathrm{nM}$ of siRNA [39]. In 2018, Ding et.al reported that gene silencing dramatically increased when concentration of the loaded siRNAs increased from 0 to $100 \mathrm{nM}$ [40]. Several studies have revealed that $100 \mathrm{nM}$ siRNA possessed high silencing efficiency [41, 42]. Therefore, we have chosen 100 nM siRNA in this work for transfection.

SSCs are a cornerstone of sperm production. However, studies and potential applications of SSCs have been greatly hampered by their low transfection efficiency. In this study,
G5 modification with cRGD not only reduced the cytotoxicity but also improved transfection efficiency in primary SSCs, raising the possibility of a receptor-mediated endocytosis manner by cRGD-integrin recognition. Integrins are able to modulate interactions between cells and the extracellular matrix by specific recognition of Arg-Gly-Asp (RGD) peptide sequence [43]. As integrins are highly expressed in SSCs [44], it makes sense that cRGD modification would improve transfection efficiency. Moreover, the cRGD-dendriplexes internalization in an SSC line can occur at $37^{\circ} \mathrm{C}$, and to a lesser extent at $4{ }^{\circ} \mathrm{C}$ or $\mathrm{NaN}_{3}$, suggesting that cRGD-dendriplexes internalization is chiefly energy- 


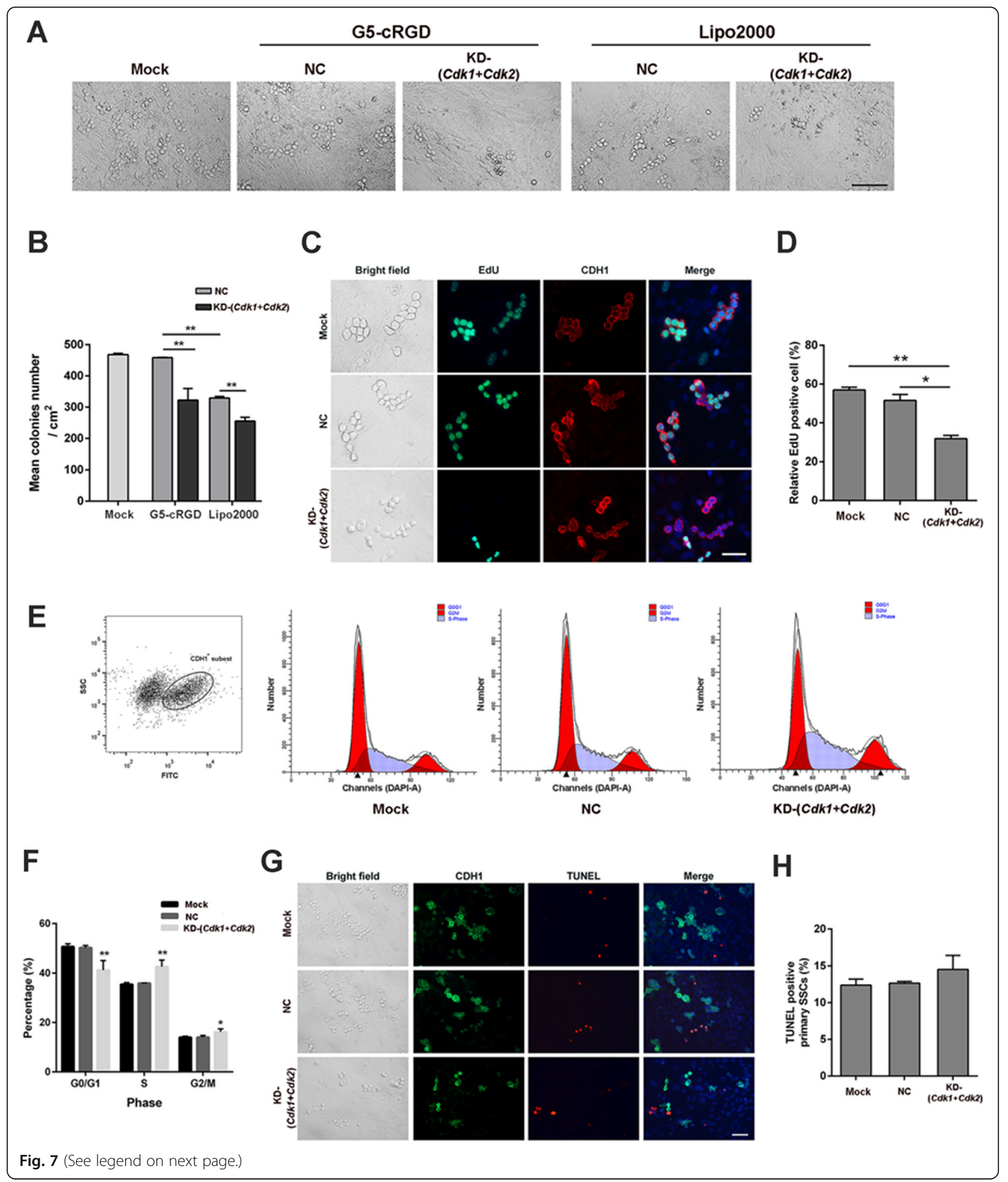


(See figure on previous page.)

Fig. 7 Functional siRNA delivery mediated by G5-cRGD leads to effective anti-proliferative effects in primary SSCs. a Appearance of cell colonies on day 5 after transfection with G5-cRGD-siRNA complexes. Lipo2000 was used as a control. Scale bars: 100 um. b The mean number of colonies (a cluster consists of more than 5 cells) per square centimeter as shown in (a). c The EdU proliferation assay was performed 7 days after transfection with scrambled siRNA or Cdk1+Cdk2 siRNA by G5-cRGD in primary SSCs. Red: CDH1 used to stain germ cell; green: EdU-positive cell; blue: Hoechst 33342 used to stain nuclei. Scale bars: 50 um. d Ratios of EdU-positive germ cells to CDH1-positive cells. e Flow cytometry analysis of cell cycle of $\mathrm{CDH}_{1}{ }^{+}$cells was performed 7 days after transfection with scrambled siRNA or Cdk1+Cdk2 siRNA by G5-cRGD. $\mathbf{f}$ Quantitation of the cell cycle of the Mock, NC, or KD-(Cdk1+Cdk2) group cells as shown in (e). TUNEL assay was presented by (g) fluorescence microscope images and (h) TUNEL-positive cell counting (\%). Red: TUNEL-positive cell; green: CDH1 was used to stain germ cell; DAPI used to stain nuclei. Scale bars: $50 \mathrm{\mu m}$. Statistical significance was assessed using one-way ANOVA followed by Dunnett's test. Data are presented as mean \pm standard deviation $(\mathrm{SD}, n=3) .{ }^{*} p<0.05,{ }^{* *} p<0.01$. Mock: untreated group; NC: scramble siRNA group; KD-(Cdk1+Cdk2): Cdk1+Cdk2 siRNA group

dependent, but a passive translocation mechanism is not completely excluded.

Indeed, high transfection efficiency does not ensure powerful gene silencing. When nano-siRNA complexes cross the cell membrane, they are mainly enwrapped in acidic vehicles such as endosomes and lysosomes. To elicit RNA interference (RNAi), siRNAs need to be released from endosomes into cytoplasm. The inside tertiary amines confer PAMAM dendrimers efficiently, facilitating the intracellular release of siRNA by the "proton sponge" effect [45]. In this study, G5-cRGD displayed higher escape ability than the original G5, indicating that $\mathrm{cRGD}$-dendriplexes were more effective for siRNAs to escape from endosomes. These results suggest that G5-cRGD may promote the endosomal escape of cRGD-dendriplexes and enhance silencing efficiency. To evaluate the delivery efficiency for gene silencing, we further co-delivered siRNAs against $C d k 1$ and $C d k 2$ that are pivotal cell cycle-regulatory molecules [46]. G5-cRGD significantly improved efficacy of gene silencing compared with the original G5. Here we demonstrated that G5-cRGD possessed high transfection efficiency, low cytotoxicity, and excellent endosomal escape ability, superior to a commercial transfection agent Lipofectamine 2000. Importantly, G5-cRGD-mediated siRNAs delivery led to downregulation of expression of $C d k 1$ and $C d k 2$, and thus a decrease in the number of proliferating cells and SSC colonies. These results are in line with previous report in tumor cells [47]. Therefore, these observations demonstrate that G5-cRGD is a promising siRNA delivery vehicle in SSCs.

Moreover, this G5-cRGD delivery system is modular and can be modified to test other genes of interest. As more promising targets for SSCs emerge, this delivery platform is poised to provide an efficient method to rapidly validate new candidate genes in primary culture SSCs. Finally, the G5-cRGD nanoparticles are also a promising delivery for other stem cells and cancer cells in which integrins are highly expressed [48].

In spite of the development, we still need to investigate the clinical application in future studies. Indeed, one needs to realize that G5-cRGD nanoparticles are prone to degrade or interact with a variety of biological proteins in the extracellular environment. Another issue is that G5-cRGD delivery system could only load small RNAs or DNA fragments. It is not likely to load large fragment plasmids, such as CRISPR-Cas9 plasmids, and thus, we need to improve its loading efficiency. In addition, currently, there are many causes of a male factor-induced subfertility, including genomic mutation. However, although it is not applicable in clinics at present, G5-cRGD delivery system exhibits potential for further clinical applications.

\section{Conclusion}

In summary, cRGD-conjugated G5 offer the advantages of nanoscale size and low toxicity, thereby holding the prospect to serve as an efficient vehicle for siRNA delivery in refractory cells including primary SSCs. Moreover, G5-cRGD-mediated delivery is safe for clinics, averting the risk of integration into the genome. In this sense, this study paves the way for future development and application of SSC auto-transplantation with genetically modified cells to clinics, with the hope of curing male infertility caused by genetic disorders.

\section{Supplementary information}

Supplementary information accompanies this paper at https://doi.org/10. 1186/s13287-019-1506-4.

Additional file 1: Figure S1. Representative of the Fourier transform infrared spectroscope (FTIR) spectrum for $\mathrm{G} 5-\mathrm{NH}_{2}$ and $\mathrm{G} 5-\mathrm{CRGD}$. Figure S2. Characterization of the SSC line C18-4 cells. Figure S3. Fluorescent microscope images of an SSC line from the cellular uptake pathway experiments. Figure S4. Endosomal escape observed by CLSM. Figure S5. Characterization of primary Sertoli cells.

\section{Abbreviations}

SSCs: Spermatogonial stem cells; PAMAM: Poly(amidoamine); G5: The fifth generation of PAMAM dendrimers; CRGD: Cyclic arginine-glycine-aspartic acid; G5-CRGD: PAMAM-CRGD dendrimers; FTIR: Fourier transform infrared spectroscope; TEM: Transmission electron microscope; CCK-8: Cell Counting Kit-8; siRNAs: Short interfering RNAs; Lipo2000: Lipofectamine ${ }^{\circledast} 2000$;

Oct4: Octamer-binding transcription factor 4; FACS: Fluorescent Activated Cell Sorting; KSR: KnockOut Serum Replacement; MEM: Minimal essential medium; GDNF: Glial cell line-derived neurotrophic factor; ICR: Institute of Cancer Research; EDC: 1-Ethyl-3-(3-dimethylaminopropyl) carbodiimide hydrochloride; NHS: N-Hydroxysuccinimide; Cdk1: Cyclin-dependent kinase 1; Cdk2: Cyclin-dependent kinase 2; NC: Scrambled siRNA; PBS: Phosphate buffer saline; MwCO: Molecular weight cut off; KBr: Potassium bromide; EDTA: Ethylenediaminetetraacetic acid; DMEM: Dulbecco's modified Eagle 
medium; FBS: Fetal bovine serum; bFGF: Basic fibroblast growth factor; N/P ratio: The ratio of nitrogen atoms in the dendrimer to phosphorous atoms in the siRNA; Dendriplexes: G5-siRNA complexes; CRGD-dendriplexes: G5-CRGDsiRNA complexes; UV: Ultraviolet; NP: Nanoparticle; FAM: 6-Carboxyfluorescein; MFI: Mean fluorescence intensity; GFP: Green fluorescent protein; $\mathrm{NaN}_{3}$ : Sodium azide; CLSM: Confocal laser scanning microscope; EdU: 5Ethynyl-2'-deoxyuridine; TUNEL: TdT-mediated dUTP Nick-End Labeling; DAPI: 4',6-Diamidino-2-phenylindole; PFA: Paraformaldehyde;

THY1: Thymocyte antigen 1; CDH1: E-cadherin; Lin28: Lin-28 homolog A; PCNA: Proliferating cell nuclear antigen; PLZF: Promyelocytic leukemia zincfinger; PEG: Polyethylene glycol

\section{Acknowledgements}

We thank Dr. Zuping He for the generous gift of mouse progenitor spermatogonia cell line C18-4 cells.

\section{Authors' contributions}

$T L$ and QC conceived the project. TL performed the project and wrote the manuscript. QC and JL synthesized the G5-CRGD nanomaterial. PZ participated in the primary SSCs experiments. $Y Z, X C$, and $Y L$ helped to revise the manuscript. All authors read and approved the final manuscript.

\section{Funding}

This study was supported in part by the National Natural Science Foundation of China (Grant No. 31572401, 31772605) to W.Z.

\section{Availability of data and materials}

All data generated or analyzed during this study are included in this published article and its additional information files.

\section{Ethics approval and consent to participate}

The experimental animals and procedures used in this study were approved by the Northwest A\&F University's Institutional Animal Care and Use Committee.

\section{Consent for publication}

Not applicable.

\section{Competing interests}

The authors declare that they have no competing interests.

Received: 22 March 2019 Revised: 15 November 2019 Accepted: 20 November 2019 Published online: 18 December 2019

\section{References}

1. Brinster RL. Germline stem cell transplantation and transgenesis. Science. 2002;296:2174-6.

2. Dym M. Spermatogonial stem cells of the testis. Proc Natl Acad Sci U S A. 1994;91:11287-9.

3. Mulder $C L$, Zheng Y, Jan SZ, Struijk RB, Repping S, Hamer G, van Pelt AM. Spermatogonial stem cell autotransplantation and germline genomic editing: a future cure for spermatogenic failure and prevention of transmission of genomic diseases. Hum Reprod Update. 2016;22:561-73.

4. Brinster RL, Zimmermann JW. Spermatogenesis following male germ-cell transplantation. Proc Natl Acad Sci U S A. 1994;91:11298-302.

5. Zheng Y, Zhang Y, Qu R, He Y, Tian X, Zeng W. Spermatogonial stem cells from domestic animals: progress and prospects. Reproduction. 2014;147: R65-74.

6. Tajik P, Hoseini Pajooh K, Fazle Elahi Z, Javdani Shahedin G, GhasemzadehNava $\mathrm{H}$. Transfection of bovine spermatogonial stem cells in vitro. Iran J Vet Res. 2017;18:113-8.

7. Kanatsu-Shinohara M, Toyokuni S, Shinohara T. Genetic selection of mouse male germline stem cells in vitro: offspring from single stem cells. Biol Reprod. 2005;72:236-40.

8. Niakan S, Heidari B, Akbari G, Nikousefat Z. Comparison of different electroporation parameters on transfection efficiency of sheep testicular cells. Cell J. 2016;18:425-37.

9. Zeng W, Tang L, Bondareva A, Luo J, Megee SO, Modelski M, Blash S, Melican DT, Destrempes MM, Overton SA, et al. Non-viral transfection of goat germline stem cells by nucleofection results in production of transgenic sperm after germ cell transplantation. Mol Reprod Dev. 2012; 79:255-61.

10. Zheng Y, Jongejan A, Mulder CL, Mastenbroek S, Repping S, Wang Y, Li J, Hamer G. Trivial role for NSMCE2 during in vitro proliferation and differentiation of male germline stem cells. Reproduction. 2017;154:181-95.

11. Baum C, Kustikova O, Modlich U, Li Z, Fehse B. Mutagenesis and oncogenesis by chromosomal insertion of gene transfer vectors. Hum Gene Ther. 2006;17:253-63.

12. Kesharwani $P$, lyer AK. Recent advances in dendrimer-based nanovectors for tumor-targeted drug and gene delivery. Drug Discov Today. 2015;20: 536-47.

13. Kesharwani P, Banerjee S, Gupta U, Amin MCIM, Padhye S, Sarkar FH, lyer AK. PAMAM dendrimers as promising nanocarriers for RNAi therapeutics. Mater Today. 2015;18:565-72.

14. Kanasty R, Dorkin JR, Vegas A, Anderson D. Delivery materials for siRNA therapeutics. Nat Mater. 2013;12:967-77.

15. Mendes LP, Pan JY, Torchilin VP. Dendrimers as Nanocarriers for Nucleic Acid and Drug Delivery in Cancer Therapy. Molecules. 2017;22:1401.

16. Ziraksaz Z, Nomani A, Soleimani M, Bakhshandeh B, Arefian E, Haririan I, Tabbakhian M. Evaluation of cationic dendrimer and lipid as transfection reagents of short RNAs for stem cell modification. Int J Pharm. 2013;448:231-8.

17. Li G, Hu Z, Yin $H$, Zhang $Y$, Huang $X$, Wang S, Li W. A novel dendritic nanocarrier of polyamidoamine-polyethylene glycol-cyclic RGD for "smart" small interfering RNA delivery and in vitro antitumor effects by human ether-a-go-go-related gene silencing in anaplastic thyroid carcinoma cells. Int J Nanomedicine. 2013;8:1293-306.

18. Waite $C L$, Roth CM. PAMAM-RGD conjugates enhance siRNA delivery through a multicellular spheroid model of malignant glioma. Bioconjug Chem. 2009:20:1908-16.

19. Kim HA, Nam K, Kim SW. Tumor targeting RGD conjugated bio-reducible polymer for VEGF siRNA expressing plasmid delivery. Biomaterials. 2014;35: 7543-52.

20. Kanatsu-Shinohara M, Ogonuki N, Inoue K, Miki H, Ogura A, Toyokuni $\mathrm{S}$, Shinohara T. Long-term proliferation in culture and germline transmission of mouse male germline stem cells. Biol Reprod. 2003;69: 612-6.

21. Hofmann MC, Braydich-Stolle L, Dettin L, Johnson E, Dym M. Immortalization of mouse germ line stem cells. Stem Cells. 2005;23:200-10.

22. Liu T, Chen X, Li T, Li X, Lyu Y, Fan X, Zhang P, Zeng W. Histone methyltransferase SETDB1 maintains survival of mouse spermatogonial stem/progenitor cells via PTEN/AKT/FOXO1 pathway. Biochim Biophys Acta Gene Regul Mech. 1860;2017:1094-102.

23. Camplejohn RS, Macartney JC, Morris RW. Measurement of S-phase fractions in lymphoid tissue comparing fresh versus paraffinembedded tissue and 4',6'-diamidino-2 phenylindole dihydrochloride versus propidium iodide staining. Cytometry. 1989;10:410-6.

24. Livak KJ, Schmittgen TD. Analysis of relative gene expression data using real-time quantitative PCR and the 2(-Delta Delta $C(T))$ method. Methods. 2001;25:402-8.

25. Zhen X, Feng X, Xie C, Zheng Y, Pu K. Surface engineering of semiconducting polymer nanoparticles for amplified photoacoustic imaging. Biomaterials. 2017;127:97-106.

26. Tokuda M, Kadokawa Y, Kurahashi H, Marunouchi T. CDH1 is a specific marker for undifferentiated spermatogonia in mouse testes. Biol Reprod. 2007;76:130-41.

27. Zheng K, Wu X, Kaestner KH, Wang PJ. The pluripotency factor LIN28 marks undifferentiated spermatogonia in mouse. BMC Dev Biol. 2009;9:38.

28. Lin D, Huang Y, Jiang Q, Zhang W, Yue X, Guo S, Xiao P, Du Q, Xing J, Deng $L$, et al. Structural contributions of blocked or grafted poly (2dimethylaminoethyl methacrylate) on PEGylated polycaprolactone nanoparticles in siRNA delivery. Biomaterials. 2011;32:8730-42.

29. Drin G, Cottin S, Blanc E, Rees AR, Temsamani J. Studies on the internalization mechanism of cationic cell-penetrating peptides. J Biol Chem. 2003;278:31192-201.

30. Costoya JA, Hobbs RM, Barna M, Cattoretti G, Manova K, Sukhwani M, Orwig KE, Wolgemuth DJ, Pandolfi PP. Essential role of Plzf in maintenance of spermatogonial stem cells. Nat Genet. 2004;36:653-9.

31. Shcharbin D, Shakhbazau A, Bryszewska M. Poly (amidoamine) dendrimer complexes as a platform for gene delivery. Expert Opin Drug Deliv. 2013;10: 1687-98. 
32. Seo SJ, Chen MW, Wang HX, Kang MS, Leong KW, Kim HW. Extra- and intracellular fate of nanocarriers under dynamic interactions with biology. Nano Today. 2017;14:84-99.

33. Kim H, Nam K, Nam JP, Kim HS, Kim YM, Joo WS, Kim SW. VEGF therapeutic gene delivery using dendrimer type bio-reducible polymer into human mesenchymal stem cells (hMSCs). J Control Release. 2015;220:222-8.

34. Li J, Liu J, Li SN, Hao YL, Chen L, Zhang XN. Antibody h-R3-dendrimer mediated siRNA has excellent endosomal escape and tumor targeted delivery ability, and represents efficient siPLK1 silencing and inhibition of cell proliferation, migration and invasion. Oncotarget. 2016;7:13782-96.

35. Prabha S, Zhou WZ, Panyam J, Labhasetwar V. Size-dependency of nanoparticle-mediated gene transfection: studies with fractionated nanoparticles. Int J Pharm. 2002;244:105-15.

36. Agashe HB, Dutta T, Garg M, Jain NK. Investigations on the toxicological profile of functionalized fifth-generation poly (propylene imine) dendrimer. J Pharm Pharmacol. 2006;58:1491-8.

37. Luong D, Kesharwani P, Deshmukh R, Mohd Amin MCl, Gupta U, Greish K, Iyer AK. PEGylated PAMAM dendrimers: enhancing efficacy and mitigating toxicity for effective anticancer drug and gene delivery. Acta Biomater. 2016; 43:14-29.

38. Arima H, Kihara F, Hirayama F, Uekama K. Enhancement of gene expression by polyamidoamine dendrimer conjugates with alpha-, beta-, and gammacyclodextrins. Bioconjug Chem. 2001;12:476-84.

39. Arima H, Tsutsumi T, Yoshimatsu A, Ikeda H, Motoyama K, Higashi T, Hirayama F, Uekama K. Inhibitory effect of siRNA complexes with polyamidoamine dendrimer/alpha-cyclodextrin conjugate (generation 3, G3) on endogenous gene expression. Eur J Pharm Sci. 2011;44:375-84.

40. Ding F, Mou Q, Ma Y, Pan G, Guo Y, Tong G, Choi CHJ, Zhu X, Zhang C. A crosslinked nucleic acid nanogel for effective siRNA delivery and antitumor therapy. Angew Chem Int Ed Engl. 2018;57:3064-8.

41. Ragelle H, Colombo S, Pourcelle V, Vanvarenberg K, Vandermeulen G, Bouzin C, Marchand-Brynaert J, Feron O, Foged C, Preat V. Intracellular siRNA delivery dynamics of integrin-targeted, PEGylated chitosan-poly (ethylene imine) hybrid nanoparticles: a mechanistic insight. J Control Release. 2015:211:1-9.

42. Tambe P, Kumar P, Karpe YA, Paknikar KM, Gajbhiye V. Triptorelin tethered multifunctional PAMAM-histidine-PEG nanoconstructs enable specific targeting and efficient gene silencing in LHRH overexpressing cancer cells. ACS Appl Mater Interfaces. 2017:9:35562-73.

43. Giancotti FG, Ruoslahti E. Integrin signaling. Science. 1999;285:1028-32.

44. Shinohara T, Avarbock MR, Brinster RL. beta1- and alpha6-integrin are surface markers on mouse spermatogonial stem cells. Proc Natl Acad Sci U S A. 1999;96:5504-9.

45. Boussif O, Lezoualc'h F, Zanta MA, Mergny MD, Scherman D, Demeneix B, Behr JP. A versatile vector for gene and oligonucleotide transfer into cells in culture and in vivo: polyethylenimine. Proc Natl Acad Sci U S A. 1995;92: 7297-301.

46. Sherr CJ. The Pezcoller lecture: cancer cell cycles revisited. Cancer Res. 2000; 60:3689-95.

47. L'Italien L, Tanudji M, Russell L, Schebye XM. Unmasking the redundancy between Cdk1 and Cdk2 at G2 phase in human cancer cell lines. Cell Cycle. 2006;5:984-93.

48. Rust WL, Carper SW, Plopper GE. The promise of integrins as effective targets for anticancer agents. J Biomed Biotechnol. 2002;2:124-30.

\section{Publisher's Note}

Springer Nature remains neutral with regard to jurisdictional claims in published maps and institutional affiliations.

Ready to submit your research? Choose BMC and benefit from:

- fast, convenient online submission

- thorough peer review by experienced researchers in your field

- rapid publication on acceptance

- support for research data, including large and complex data types

- gold Open Access which fosters wider collaboration and increased citations

- maximum visibility for your research: over $100 \mathrm{M}$ website views per year

At BMC, research is always in progress.

Learn more biomedcentral.com/submissions 